\title{
Preparation of PANI-CuZnO ternary nanocomposite and investigation of its effects on polyurethane coatings antibacterial, antistatic, and mechanical properties
}

\author{
Abdolreza Mirmohseni $^{1}$ (D) $\cdot$ Mortaza Rastgar $^{1} \cdot$ Ali Olad $^{1}$
}

Received: 5 October 2018 / Accepted: 21 November 2018 / Published online: 30 November 2018

(c) The Author(s) 2018

\begin{abstract}
In this study, a facile method for the production of Antibacterial and Antistatic polyurethane coatings was investigated using copper modified $\mathrm{ZnO}$ nanoparticles-polyaniline nanofibers (PANI-CuZnO) ternary nanocomposite. PANI-CuZnO ternary nanocomposite was synthesized through two steps. First, copper-modified $\mathrm{ZnO}$ nanoparticles were produced through the hydrolysis method using acetate precursors, and then they were mixed with polyaniline nanofibers, which were synthesized by seeding method. The obtained nanocomposite was characterized by FTIR, XRD, and FESEM techniques. Results of evaluating the antibacterial action of the polyurethane coatings with the content of ternary nanocomposite showed that the obtained coatings have a proper antibacterial action against Gram-positive and Gram-negative bacteria. In addition, measuring the coatings' surface electrical resistance revealed that addition of the ternary nanocomposite to the polyurethane coatings' matrix causes the surface electrical resistance of the coatings significantly decreases and reaches $8 \times 10^{7} \Omega / \mathrm{sq}$. Thereby, they could be categorized as an antistatic coating. Moreover, the addition of PANI-CuZnO enhanced adhesion strength and scratch resistance of the final polyurethane coatings.
\end{abstract}

\section{Graphical abstract}

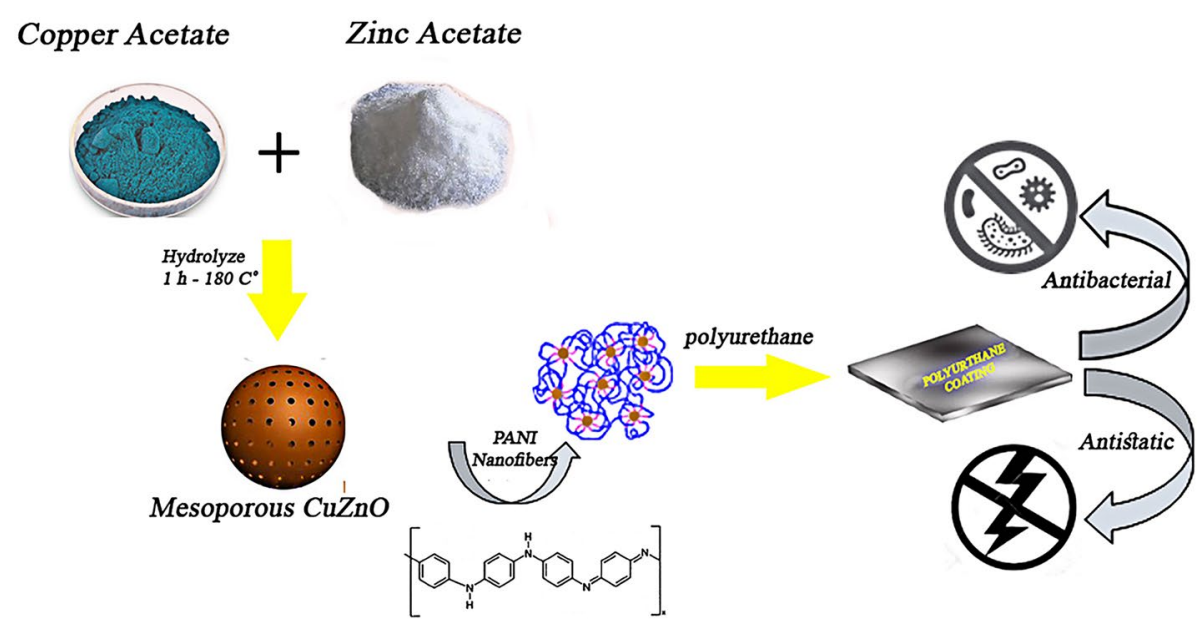

Keywords Ternary nanocomposite $\cdot$ Modified $\mathrm{ZnO}$ nanoparticles $\cdot$ Polyaniline nanofibers $\cdot$ Antibacterial $\cdot$ Antistatic

Abdolreza Mirmohseni

mirmohseni@tabrizu.ac.ir

1 Department of Applied Chemistry, Faculty of Chemistry,

University of Tabriz, Tabriz 51666-16471, Iran 


\section{Introduction}

Nowadays, human's life is always under threat of different infectious agents, and bacterial species have a major role in the emergence of such infections and their consequences. Considering bacteria adhesion to different surfaces as one of the main stages in bacterial species' growth and proliferation processes, developing antibacterial surfaces have an undeniable effect on preventing damages caused by bacteria growth [1]. Moreover, increase in resistance of bacterial species to the common antibacterial agents leads to a growing demand for novel and effective antibacterial agents for the production of antibacterial coatings [2-4]. In some industries, especially in the chemical and pharmaceutical industries, utilizing the coatings with antibacterial and antistatic properties would be necessary to safety and efficacy of such plants to be guaranteed [5]. In this regard, nanocomposite material owing to their improved physical and chemical properties could be counted as a proper choice for creating antibacterial and antistatic properties in polymer coatings $[5,6]$.

Studies showed that $\mathrm{ZnO}$ nanoparticles have an effective antibacterial property against different bacteria and have a good compatibility with human cells and have no toxic effect on mammalians' cells [7]. Moreover, $\mathrm{ZnO}$ nanoparticles modification with some transition metals causes an enhancement in efficacy and antibacterial action of these nanoparticles. Among different metals, copper due to its advantages like low cost, accessibility, and proper antibacterial property has gained much attention [8]. Antibacterial mechanism of action of copper could be originated from creating active oxygen species and disrupting bacterial cells' membrane processes [9, 10]. Modification of $\mathrm{ZnO}$ nanoparticles by $\mathrm{Cu}$ ions can improve the antibacterial property of resultant nanohybrids [11]. Moreover, the presence of $\mathrm{ZnO}$ nanoparticles in polymer coatings matrix could noticeably increase the produced coatings mechanical properties $[12,13]$.

Polyaniline owing to benefiting from high environmental stability, facile synthesis method, and low production cost is counted as one of the most used conducting polymers. With regard to these unique characteristics, polyaniline could have applications in various fields like sensors, batteries, wastewater treatment, anticorrosion coatings, and antistatic coatings [14-20]. Furthermore, polyaniline's different shapes with regard to their improved properties could, even more, increase its applicability. For example, polyaniline production in nanofiber and nanowire forms causes improvement in its electrical conductivity [21, 22]. Addition of inorganic nanoparticles to polyaniline's matrix leads to increased electrical conductivity and efficacy of polyaniline to be utilized in antistatic coatings production
[23]. Addition of $\mathrm{ZnO}$ nanoparticles would also have a noticeable effect on increasing polyaniline's electrical conductivity and its electrical efficiency [24].

In current research work, mesoporous copper-modified $\mathrm{ZnO}$ nanoparticles were produced through the hydrolysis method. Then, polyaniline nanofibers were synthesized through the seeding method and were mixed with modified $\mathrm{ZnO}$ nanoparticles to obtain PANI-CuZnO ternary nanocomposite. Afterwards, the produced ternary nanocomposite was utilized in polyurethane resin's matrix and antibacterial and antistatic properties of the produced coatings were evaluated. Moreover, the effect of ternary nanocomposite on the improvement of final coatings' adhesion strength and scratch resistance was also investigated.

\section{Experimental}

\section{Materials and reagents}

Zinc acetate dihydrate ( $\geq 99 \%)$, copper acetate ( $\geq 98 \%)$, diethylene glycol (DEG $\geq 99 \%$ ), polyethylene glycol $\left(M_{\mathrm{w}}=400\right.$, pure), ammonium persulfate salt ( $\left.\geq 99 \%\right)$, aniline ( $\geq 99 \%)$, and hydrochloric acid (37\%) were purchased from Merck. Aniline was double distillates prior to use. The Polyester polyol (technical grade) and Polymeric Methylene Diphenyl Diisocyanate (PMDI, technical grade) were provided by Bayer.

\section{Synthesis of Cu-modified ZnO nanoparticles}

To produce copper-modified $\mathrm{ZnO}$ nanoparticles, zinc acetate dihydrate was hydrolyzed in the presence of copper acetate salt (10 wt\% of zinc acetate) in diethylene glycol (DEG) as the reaction medium. For this purpose, $2 \mathrm{mmol}$ of zinc acetate along with copper acetate were added to $25 \mathrm{ml}$ DEG. Then, $0.5 \mathrm{~g}$ PEG was added to the reaction medium and the resulting mixture was refluxed up to $170-180{ }^{\circ} \mathrm{C}$ for $1 \mathrm{~h}$. After completion of the reaction, the reactor was cooled and participates were centrifuged and washed by deionized water, ethanol, and acetone, respectively. Finally, the products were dried at $80{ }^{\circ} \mathrm{C}$ for $2 \mathrm{~h}$.

\section{Synthesis of PANI nanofibers}

Polyaniline nanofibers were synthesized by the seeding method. First, $0.0037 \mathrm{~g}$ of aniline monomers were dispersed in $50 \mathrm{ml} 1 \mathrm{M} \mathrm{HCl}$ solution. Then, $0.0045 \mathrm{~g}$ of ammonium persulfate (aniline:APS molar ratio is 2:1) was dissolved in $1 \mathrm{M} \mathrm{HCl}$ solution and was added to the above mixture. Final mixture's temperature was kept at $0{ }^{\circ} \mathrm{C}$ (using a refrigerator and an ice bath) and left to rest for $48 \mathrm{~h}$. After completion of the polymerization reaction, participates were collected 
and washed by DI water and ethanol, respectively and dried at $60{ }^{\circ} \mathrm{C}$ for $12 \mathrm{~h}$.

\section{Preparation of PANI-CuZnO ternary nanocomposite}

To prepare PANI-CuZnO ternary nanocomposite, first, the desired amount of PANI nanofibers $(0.5 \mathrm{~g})$ were added to DI water and then an equal amount of modified $\mathrm{ZnO}$ nanoparticles were added to this mixture and homogenized by the ultrasonic method for 10 min (PANI:CuZnO ratio $=1: 1$ ). Finally, the resultant participates were collected and dried at $60{ }^{\circ} \mathrm{C}$ for $6 \mathrm{~h}$.

\section{Production of polyurethane coatings}

Polyurethane coatings with antibacterial and antistatic properties were produced by adding appropriate amounts of PANI-CuZnO ternary nanocomposite (equal to 1,2 , 3 and $5 \mathrm{wt} \%$ ) to the $10 \mathrm{~g}$ of polyester polyol and mixing with a mechanical stirrer. Then, $2 \mathrm{~g}$ PMDI was added to the obtained mixture and after gently mixing for several minutes, the final mixture was applied to glass plates and after $24 \mathrm{~h}$, polyurethane films were detached from the glass plates for further studies.

\section{Characterization}

FTIR spectra of the modified $\mathrm{ZnO}$ nanoparticles and PANI-CuZnO ternary nanocomposite were collected by Perkin-Elmer (USA) in the range of $400-4000 \mathrm{~cm}^{-1}$. X-ray diffraction patterns of the samples were recorded by D8 Advance-Bruker (Germany). Modified $\mathrm{ZnO}$ nanoparticles and PANI-CuZnO ternary nanocomposite's morphological properties were studied by TeScan-Mira III microscope (Czech Republic).

\section{Antibacterial testing}

The antibacterial property of the produced coatings was investigated against Escherichia coli as a Gram-negative and Staphylococcus aureus as Gram-positive bacteria. For this purpose, the plate colony counting method was utilized. First, original bacterial suspensions were diluted to $10^{8} \mathrm{CFU} / \mathrm{ml}$ using nutrient broth. Then $0.1 \mathrm{ml}$ of diluted bacterial suspensions was transferred to vessels containing $0.9 \mathrm{ml}$ of physiological serum $(0.9 \% \mathrm{NaCl}$ solution). Pure polyurethane and polyurethane with the content of PANI and PANI-CuZnO ternary nanocomposite was applied to the sterile paper blank discs and they were put in contact with the bacteria contained solutions. After $1 \mathrm{~h}$, these solutions were ten times diluted by consecutive addition of $0.1 \mathrm{ml}$ of solution from one vessel to another vessel with the content of physiological serum. Finally, $0.1 \mathrm{ml}$ solution from each vessel was applied on plates with the content of solidified agar. The plates were incubated at $37^{\circ} \mathrm{C}$ for $24 \mathrm{~h}$. Finally, the number of formed bacterial colonies was counted.

\section{Evaluation of the coatings' antistatic property}

To investigate the antistatic property of the produced coatings, measuring the coatings' surface electrical resistance based on ASTM D257 was conducted. For this purpose, the two-point probe technique was used. A Digital Insulation Tester (MASTECH MS5203) along with two steel probes was used to determine the surface electrical resistance of pure polyurethane coating and the coatings with the content of PANI and PANI-CuZnO ternary nanocomposite. A constant electrical potential $(500 \mathrm{~V})$ was applied to the polymer films and their antistatic behavior was evaluated by calculating surface electrical resistance by means of Eq. 1

$R_{\mathrm{s}}=\frac{p}{g} \times R_{\mathrm{R}}$

where $R_{\mathrm{S}}$ is surface electrical resistance ( $\Omega$ per square), $R_{\mathrm{R}}$ is the recorded electrical resistance $(\Omega), P$ is the used probes' parameter $(\mathrm{cm})$ and $\mathrm{g}$ is the distance between inner electrodes $(\mathrm{cm})$.

\section{Measuring coatings' adhesion strength and scratch resistance}

The strength of polyurethane coatings adhesion to the concrete substrates was studied by the pull-off method based on ASTM D4541. In this method, tensile Dollies were glued to the coating, when the adhesive cured, the force required to pull the coating off the surface was measured. To evaluate the scratch resistance of the coatings, based on ISO 1518 standard, a pen hardness tester was utilized. In this method, a pen-like device with a tungsten carbide tip was drawn over the coating's surface with a defined constant pressure. A pressure needed for creating a scratch on the coatings' surface was reported as the coatings' scratch resistance.

\section{Results and discussion}

\section{Evaluating the coatings antibacterial property}

Antibacterial action of the prepared coatings was tested against $S$. aureus (Gram-positive) and E. coli (Gram-negative) bacteria. The polyurethane coatings with $5 \mathrm{wt} \%$ content of PANI nanofibers and PANI-CuZnO nanocomposite were put in contact with bacterial strains and the pure polyurethane sample was used as a control. The results of observing bacterial colonies growth after 60-min exposure to the coating samples are summarized in Table 1 . The 
Table 1 The antibacterial property of the polyurethane coatings with $5 \mathrm{wt} \%$ content of PANI nanofibers and PANI-CuZnO ternary nanocomposite after 60-min exposure to the bacterial strains

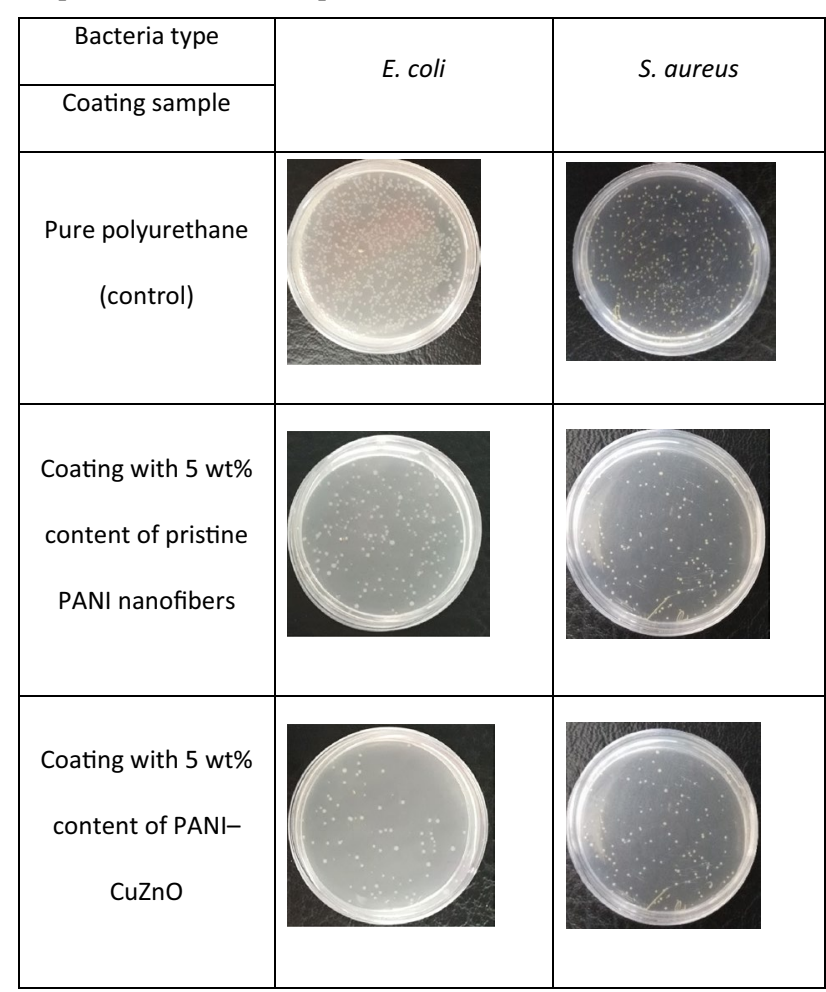

small white dots represent bacterial colonies. As it is obvious in the plates with the content of three times diluted bacterial suspension, the polyurethane coating with $5 \mathrm{wt} \%$ content of ternary nanocomposite have greatly reduced the number of the grown colonies. While the pure polyurethane coating and the coating with the content of PANI have not had a noticeable effect on the reduction of bacterial colonies. The results show the presence of $\mathrm{ZnO}$ nanoparticles, $\mathrm{Cu}$ ions and polyaniline nanofibers could have a synergistic effect on coatings antibacterial property. Along with the presence of $\mathrm{ZnO}$ nanoparticles, $\mathrm{Cu}$ ions releasing form the ternary nanocomposite and their interactions with phosphor/sulfur contained proteins could be the main factor in disrupting bacteria's vital processes [25]. In case of Gram-negative bacteria, reduction in bacterial colonies was less than compared to Gram-positive one which shows the lower vulnerability of the Gram-negative bacteria to the ternary nanocomposite. Presence of a lipopolysaccharide membrane in Gram-negative bacteria could be a reason for their higher resistance against structural damages [26]. In addition, Fig. 1 quantitatively shows reduction percent in the number of colonies after 60-min exposure to the polyurethane coatings.

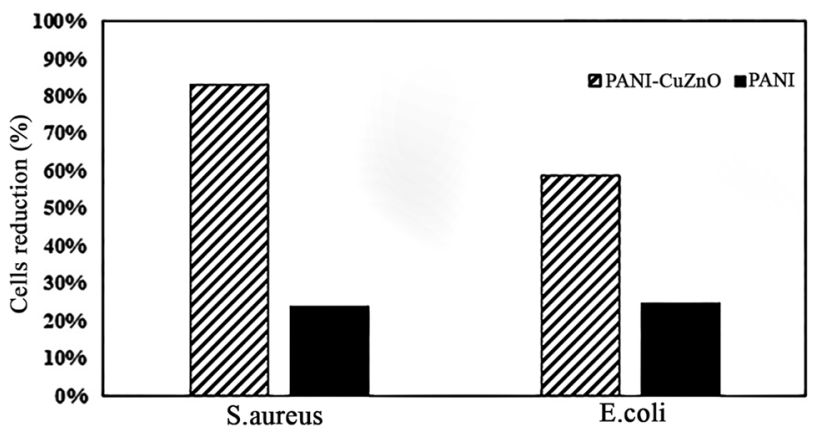

Fig. 1 Bacterial colonies reduction after 60-min contact with PANI nanofibers and PANI-CuZnO ternary nanocomposite

\section{Evaluating antistatic property}

Figure 2 shows polyurethane coatings' surface electrical resistance as a function of PANI and PANI-CuZnO ternary nanocomposite content. Measuring the surface resistance of the pure polyurethane coating and the coating with the content of pure $\mathrm{ZnO}$ nanoparticles showed that these coatings have a very high surface resistance which was out of the antistatic coatings' surface electrical resistance range.
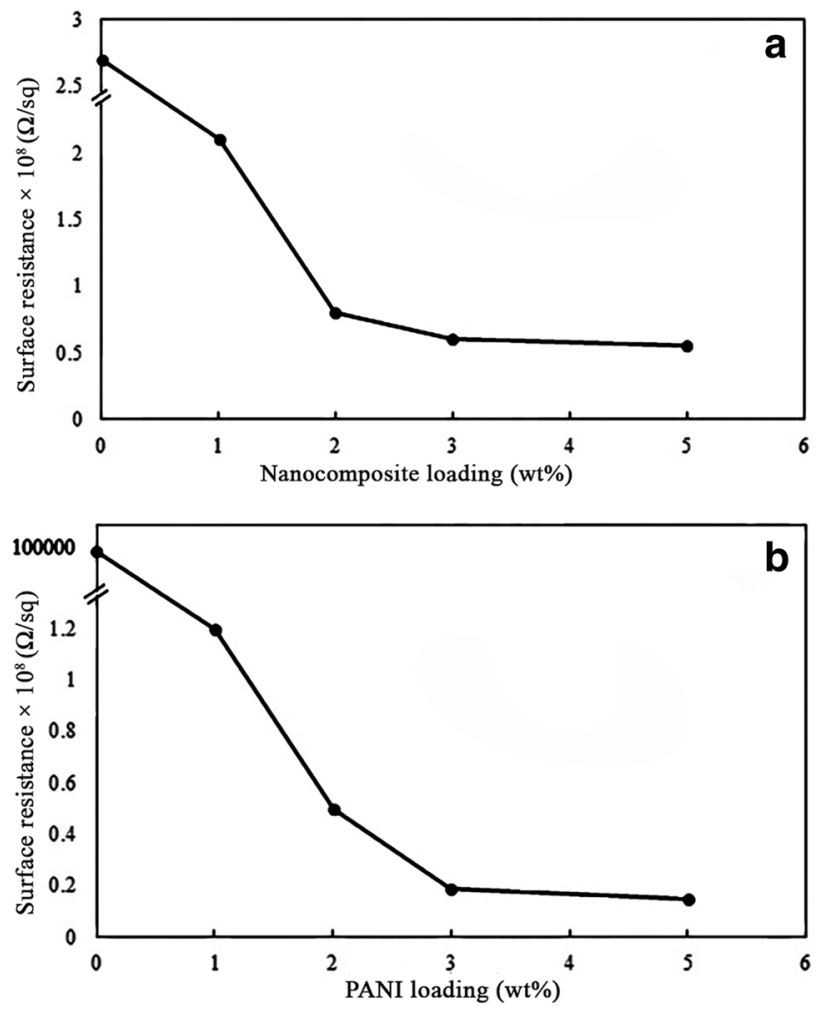

Fig. 2 Surface electrical resistance of the polyurethane coatings as a function of a PANI-CuZnO ternary nanocomposite, b PANI nanofibers 
As Fig. 2a shows, the surface resistance of the polyurethane coatings gradually decrease by increasing the amount of ternary nanocomposite in the coatings' matrix. A low percolation threshold about $2 \mathrm{wt} \%$ nanocomposite loading is observed in the polyurethane coating and the slope of reduction in surface resistivity is reduced. Theoretically, at the low amount of conductive additive, there is no possibility for the creation of conduction pathways in the polymer matrix and the coating will show high surface resistance. By increasing the content of PANI-CuZnO nanocomposite to reach the percolation threshold, three-dimensional conduction pathways are created throughout the matrix and surface electrical resistance of the coatings begins to reduce [27]. According to the literature, antistatic coatings have a surface resistance between $10^{5}$ and $10^{9} \Omega / \mathrm{sq}$ [28]. Adding $2 \mathrm{wt} \%$ ternary nanocomposite leads to the obtained polyurethane coating's surface resistance reach $8 \times 10^{8} \Omega /$ sq, therefore, it could be counted as an antistatic coating. To evaluate the efficacy of PANI-CuZnO ternary nanocomposite to be used as an antistatic agent, the surface electrical resistance of the coatings with the content of pristine polyaniline was also investigated. As it is clear in Fig. 2b, the coatings containing the same amount of pristine PANI have a higher surface electrical resistance. Therefore, it can be concluded that PANI-CuZnO has a higher efficacy for the creation of antistatic property in polyurethane coatings. This higher efficacy could be attributed to the synergistic effect of $\mathrm{ZnO}$ nanoparticles, $\mathrm{Cu}$ ions and PANI nanofibers.

\section{FTIR studies}

The molecular structure of PANI nanofibers and PANI-CuZnO ternary nanocomposite was investigated by FTIR spectroscopy and the results are illustrated in Fig. 3. Curve a, in Fig. 3, represents FTIR spectrum of PANI nanofibers. The absorption peaks at $1502 \mathrm{~cm}^{-1}$ and $1580 \mathrm{~cm}^{-1}$ are attributed to $\mathrm{C}=\mathrm{C}$ and $\mathrm{C}=\mathrm{N}$ stretching vibrations of benzenoid and quinoid rings in PANI chains, respectively. The peaks around $1304 \mathrm{~cm}^{-1}$ and $3500 \mathrm{~cm}^{-1}$ are respectively related to bending vibrations of $\mathrm{C}-\mathrm{N}$ and $\mathrm{N}-\mathrm{H}$. In addition, the peak at $1100 \mathrm{~cm}^{-1}$ could be originated from quinoid units of PANI chains [29]. The FTIR spectrum of PANI-CuZnO ternary nanocomposite is shown in curve b. As it is obvious, the peak at $3300 \mathrm{~cm}^{-1}$ originates from stretching vibrations of $\mathrm{OH}$ groups which are existed on the $\mathrm{ZnO}$ nanoparticles surface. While all PANI's characteristics peaks are obvious in curve $b$, all these peaks have experienced a slight shift to the lower wavenumbers which is because of some interactions like hydrogen bond between PANI chains and modified $\mathrm{ZnO}$ nanoparticles [24]. These interactions could be a reason for the improved electrical conductivity of the PANI-CuZnO nanocomposite for the

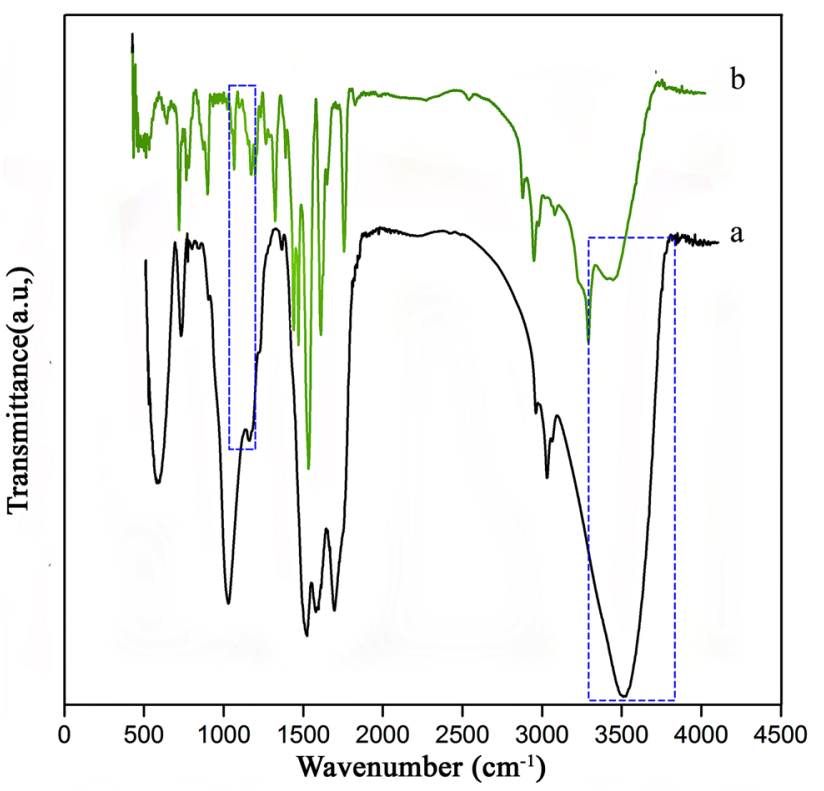

Fig. 3 FTIR spectrum of a PANI nanofibers, $\mathbf{b}$ PANI-CuZnO ternary nanocomposite

creation of better antistatic property in the polyurethane coatings.

\section{XRD analysis}

To confirm $\mathrm{ZnO}$ nanoparticles synthesis and also evaluate the crystallographic properties of the PANI-CuZnO ternary nanocomposite, $\mathrm{X}$-ray diffraction pattern analysis was utilized (Fig. 4). Curve a shows X-ray diffraction pattern of copper-modified $\mathrm{ZnO}$ nanoparticles. The peaks which are appeared at $2 \theta=31^{\circ}, 34^{\circ}, 36^{\circ}, 47^{\circ}, 56^{\circ}, 62^{\circ}$ and $67^{\circ}$ respectively relate to diffraction from (100), (002), (101), (102), (110), (103), and (112) planes of $\mathrm{ZnO}$ nanoparticles. These peaks clearly show that $\mathrm{ZnO}$ nanoparticles are fully fabricated through the synthesis method using acetate precursors [30]. Moreover, the peak at $2 \theta=45^{\circ}$ could be appeared because of the diffraction from (202) plane of $\mathrm{CuO}$ which may exist as an impurity in the nanocomposite structure. In curve $\mathrm{b}$ which corresponds to PANI-CuZnO ternary nanocomposite, two wide diffraction peaks appeared at $2 \theta=19^{\circ}$ and $25^{\circ}$ shows the amorphous structure of the conductive polymer due to the repetition of benzenoid and quinoid rings in PANI chains [31]. In addition, the presence of all diffraction peaks related to $\mathrm{ZnO}$ nanoparticles shows that the crystalline structure of modified $\mathrm{ZnO}$ nanoparticles is preserved in the presence of PANI chains. It can be concluded that PANI chains are properly located beside $\mathrm{ZnO}$ nanoparticles and they have not had an adverse effect on the structural properties of $\mathrm{ZnO}$ nanoparticles. 


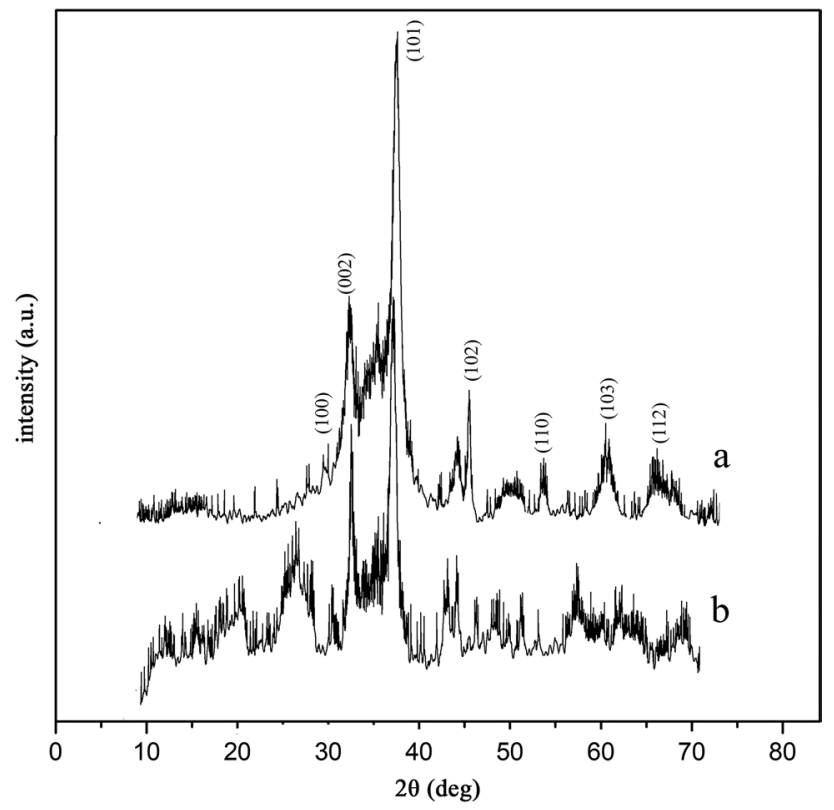

Fig. 4 X-ray diffraction patterns of a copper-modified $\mathrm{ZnO}$ nanoparticles, b PANI-CuZnO ternary nanocomposite

\section{Morphological studies}

Morphological characteristics of the copper-modified $\mathrm{ZnO}$ nanoparticles, PANI nanofibers, and PANI-CuZnO ternary nanocomposite were investigated by FESEM technique (Fig. 5). FESEM images of the modified $\mathrm{ZnO}$ nanoparticles are illustrated in Fig. 5a, b. As it is clear, these nanoparticles have a special shape and mesoporous structure which shows the utilized synthesis method has a high efficacy for production of mesoporous copper-modified $\mathrm{ZnO}$ nanoparticles. The mesoporous surface of $\mathrm{ZnO}$ nanoparticles leads to the enhanced surface area of these nanoparticles to interact with PANI chains which finally improves the final ternary nanocomposite's properties. FESEM image of PANI nanofibers shows the seeding method could produce PANI nanofibers with uniform size distribution (Fig. 5c). The FESEM image of PANI-CuZnO nanocomposite is shown in Fig. 5d and distribution of mesoporous-modified $\mathrm{ZnO}$ nanoparticles among PANI chains are clear. This uniform location of $\mathrm{ZnO}$ nanoparticles among PANI chains could cause improved properties of PANI to be utilized as an antistatic and antibacterial agent in the polyurethane coatings matrix.

\section{Evaluation of the coatings' adhesion strength and scratch resistance}

A coating's adhesion strength to the substrate is one of the main factors for improving the coating's efficacy and longevity. Therefore, the effect of adding PANI-CuZnO ternary nanocomposite on the improvement of polyurethane coatings adhesion strength to a concrete substrate was studied. The results of adhesion strength of the pure polyurethane coatings and the coatings with 3 and $5 \mathrm{wt} \%$ content of ternary nanocomposite are summarized in Table 2. As the results of Pull Off test show, by increasing the content of ternary nanocomposite, the adhesion strength of the coatings is increased. This improvement could be attributed to the $\mathrm{ZnO}$ nanoparticles bilateral interactions with polyurethane chains and active $\mathrm{OH}$ groups on the substrate's surface [12]. Moreover, the scratch resistance of the coatings is another factor that affects their performance and appearance. The results of investigating the scratch resistance of the prepared polyurethane coatings revealed that increased content of ternary nanocomposite would lead to improved scratch resistance of the coatings. This improvement results from the interactions between $\mathrm{ZnO}$ nanoparticle and polyurethane chains which compact the polyurethane chains and increase their resistance against tearing [32].

\section{Conclusion}

The significance of this study was synthesizing PANI-CuZnO ternary nanocomposite and its utilization as a multifunctional additive for creating antistatic and antibacterial properties in polyurethane coatings. This ternary nanocomposite was produced using copper-modified $\mathrm{ZnO}$ nanoparticles and PANI nanofibers and through the two facile steps. The obtained nanocomposite was characterized in term of structural, crystallographic, and morphological properties. The antibacterial and antistatic coatings were produced by addition of the ternary nanocomposite to the polyurethane matrix. Evaluation of the coatings' antibacterial property showed that the produced coatings have a proper ability to inhibit Gram-positive S. aureus and Gramnegative $E$. coli bacteria growth. In addition, utilizing $2 \mathrm{wt} \%$ ternary nanocomposite in the polyurethane coating led to the coating's surface electrical resistance reached $8 \times 10^{7} \Omega /$ sq which caused the obtained coating could be categorized as an antistatic coating. Moreover, increasing the content 


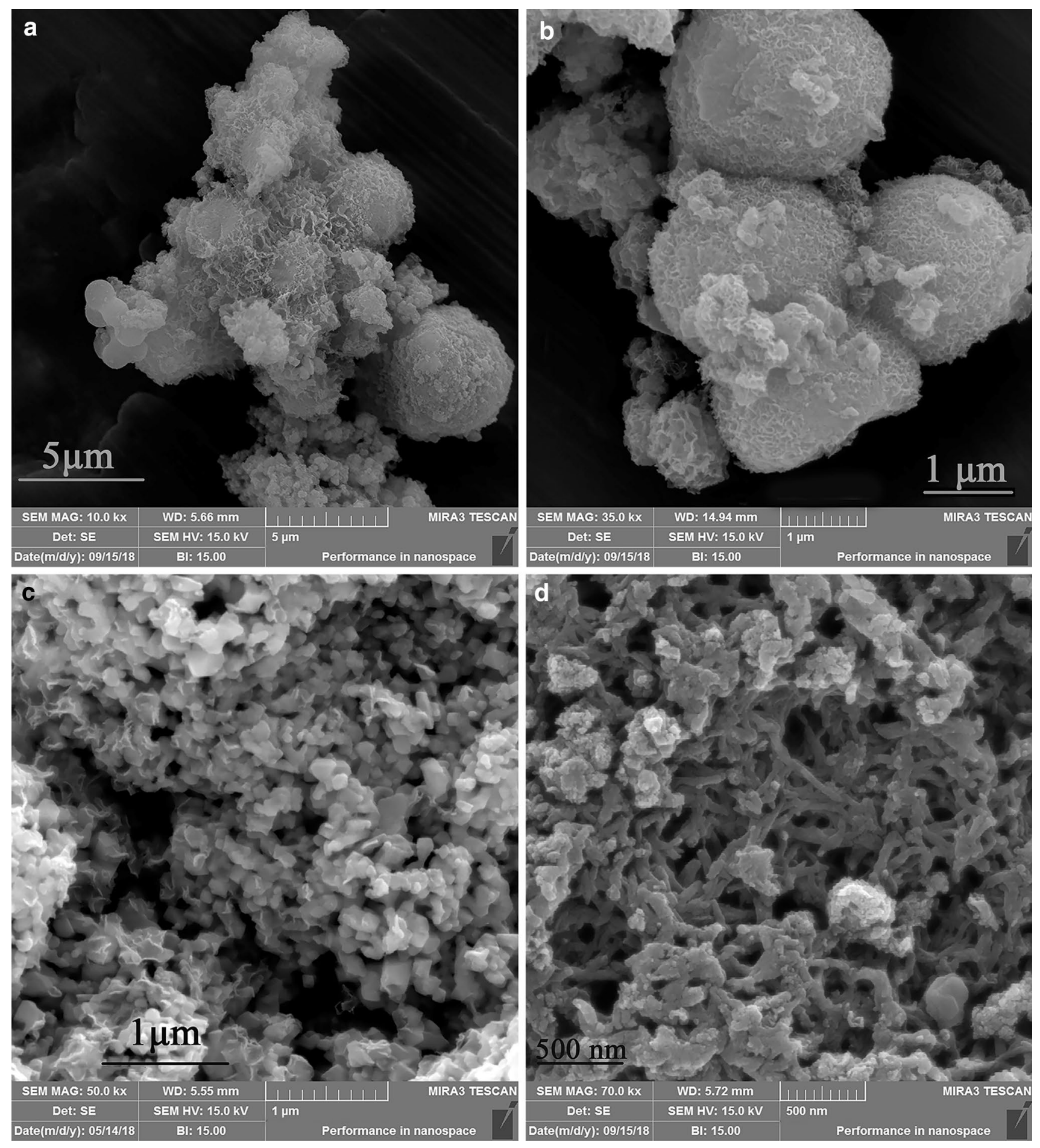

Fig. 5 FESEM images of $\mathbf{a}, \mathbf{b}$ copper-modified ZnO nanoparticles, $\mathbf{c}$ PANI nanofibers, $\mathbf{d}$ PANI-CuZnO ternary nanocomposite 
Table 2 The results of measuring adhesion strength and scratch resistance of the pure polyurethane coating and the coatings with 3 and $5 \mathrm{wt} \%$ content of PANI-CuZnO ternary nanocomposite

\begin{tabular}{lll}
\hline Mechanical properties & \\
\hline $\begin{array}{l}\text { Nanocomposite content in the } \\
\text { coating (\%) }\end{array}$ & $\begin{array}{l}\text { Adhesion strength } \\
(\mathrm{MPa})\end{array}$ & $\begin{array}{l}\text { Scratch } \\
\text { resistance } \\
(\mathrm{N})\end{array}$ \\
\hline 0 & 1.9 & 600 \\
3 & 2.5 & 850 \\
5 & 3.0 & 1000 \\
\hline
\end{tabular}

of ternary nanocomposite resulted in improved adhesion strength and scratch resistance of the polyurethane coatings.

Acknowledgements The authors greatly acknowledge the financial support of the University of Tabriz.

Open Access This article is distributed under the terms of the Creative Commons Attribution 4.0 International License (http://creativeco mmons.org/licenses/by/4.0/), which permits unrestricted use, distribution, and reproduction in any medium, provided you give appropriate credit to the original author(s) and the source, provide a link to the Creative Commons license, and indicate if changes were made.

\section{References}

1. Gupta, J., Bahadur, D.: Visible light sensitive mesoporous $\mathrm{Cu}-$ substituted $\mathrm{ZnO}$ nanoassembly for enhanced photocatalysis, bacterial inhibition, and noninvasive tumor regression. ACS Sustain. Chem. Eng. 5, 8702-8709 (2017)

2. Bogdanovic, U., Vodnik, V., Mitric, M., Dimitrijevic, S., Skapin, S.D., Zunic, V., Budimir, M., Stoiljkovic, M.: Nanomaterial with high antimicrobial efficacy-copper/polyaniline nanocomposite. ACS Appl. Mater. Interfaces. 7, 1955-1966 (2015)

3. Kasithevar, M., Periakaruppan, P., Muthupandian, S., Mohan, M.: Antibacterial efficacy of silver nanoparticles against multidrug resistant clinical isolates from post-surgical wound infections. Microb. Pathog. 107, 327-334 (2017)

4. Saravanan, M., Jacob, V., Arockiaraj, J., Prakash, P.: Extracellular biosynthesis, characterization and antibacterial activity of silver nanoparticles synthesized by Bacillus subtilis (NCIM2266). J. Bionanosci. 8, 21-27 (2014)

5. Wang, J., Zhang, C., Du, Z., Li, H., Zou, W.: Functionalization of MWCNTs with silver nanoparticles decorated polypyrrole and their application in antistatic and thermal conductive epoxy matrix nanocomposite. RSC Adv. 6, 31782-31789 (2016)

6. Mostafaei, A., Nasirpouri, F.: Preparation and characterization of a novel conducting nanocomposite blended with epoxy coating for antifouling and antibacterial applications. J. Coat. Technol. Res. 10, 679-694 (2013)

7. Krishnamurthi, P., Raju, Y., Khambhaty, Y., Manoharan, P.T.: Zinc oxide-supported copper clusters with high biocidal efficacy for Escherichia coli and Bacillus cereus. ACS Omega 2, 2524-2535 (2017)

8. Vellaichamy, B., Periakaruppan, P., Ponnaiah, S.K.: A new in situ synthesized ternary CuNPs-PANI-GO nano composite for selective detection of carcinogenic hydrazine. Sens. Actuator B Chem. 245, 156-165 (2017)

9. Kruk, T., Szczepanowicz, K., Stefańska, J., Socha, R.P., Warszyński, P.: Synthesis and antimicrobial activity of monodisperse copper nanoparticles. Colloids Surf. B 128, 17-22 (2015)

10. Padmavathy, N., Samantaray, P.K., Ghosh, L.D., Madras, G., Bose, S.: Selective cleavage of the polyphosphoester in crosslinked copper based nanogels: enhanced antibacterial performance through controlled release of copper. Nanoscale 9, 12664-12676 (2017)

11. Bhuyan, T., Khanuja, M., Sharma, R., Patel, S., Reddy, M., Anand, S., Varma, A.: A comparative study of pure and copper $(\mathrm{Cu})$-doped $\mathrm{ZnO}$ nanorods for antibacterial and photocatalytic applications with their mechanism of action. J. Nanoparticle Res. 17, 288 (2015)

12. El Saeed, A.M., El-Fattah, M.A., Azzam, A.M.: Synthesis of ZnO nanoparticles and studying its influence on the antimicrobial, anticorrosion and mechanical behavior of polyurethane composite for surface coating. Dyes Pigments 121, 282-289 (2015)

13. Jena, K.K., Narayan, R., Raju, K.: Surface functionalized zinc oxide $(\mathrm{ZnO})$ nanoparticle filled organic-inorganic hybrid materials with enhanced thermo-mechanical properties. Prog. Org. Coat. 89, 82-90 (2015)

14. Jha, R.K., Wan, M., Jacob, C., Guha, P.K.: Ammonia vapour sensing properties of in situ polymerized conducting PANI-nanofiber/ WS 2 nanosheet composites. New J. Chem. 42, 735-745 (2018)

15. Ponnaiah, S.K., Periakaruppan, P., Vellaichamy, B.: New electrochemical sensor based on a silver-doped iron oxide nanocomposite coupled with polyaniline and its sensing application for picomolar-level detection of uric acid in human blood and urine samples. J. Phys. Chem. B 122, 3037-3046 (2018)

16. Yuan, G., Pan, J., Zhang, Y., Yu, J., He, Y., Su, Y., Zhou, Q., Jin, H., Xie, S.: Sepiolite/CNT/S @ PANI composite with stable network structure for high performance lithium sulfur batteries. RSC Adv. 8, 17950-17957 (2018)

17. Prasankumar, T., Wiston, B.R., Gautam, C., Ilangovan, R., Jose, S.P.: Synthesis and enhanced electrochemical performance of PANI/ $/ \mathrm{Fe}_{3} \mathrm{O}_{4}$ nanocomposite as supercapacitor electrode. J. Alloys Compd. 757, 466-475 (2018)

18. Ramachandran, A., Prasankumar, T., Sivaprakash, S., Wiston, B.R., Biradar, S., Jose, S.: Removal of elevated level of chromium in groundwater by the fabricated $\mathrm{PANI} / \mathrm{Fe}_{3} \mathrm{O}_{4}$ nanocomposites. Environ. Sci. Pollut. Res. 24, 7490-7498 (2017)

19. Lin, Y.-T., Don, T.-M., Wong, C.-J., Meng, F.-C., Lin, Y.-J., Lee, S.-Y., Lee, C.-F., Chiu, W.-Y.: Improvement of mechanical properties and anticorrosion performance of epoxy coatings by the introduction of polyaniline/graphene composite. Surf. Coat. Technol. (2018). https://doi.org/10.1016/j.surfcoat.2018.01.050

20. Zhu, A., Wang, H., Sun, S., Zhang, C.: The synthesis and antistatic, anticorrosive properties of polyaniline composite coating. Prog. Org. Coat. 122, 270-279 (2018)

21. Tissera, N.D., Wijesena, R.N., Rathnayake, S., de Silva, R.M., de Silva, K.N.: Heterogeneous in situ polymerization of polyaniline (PANI) nanofibers on cotton textiles: improved electrical conductivity, electrical switching, and tuning properties. Carbohydr. Polym. 186, 35-44 (2018)

22. Mao, N., Chen, W., Meng, J., Li, Y., Zhang, K., Qin, X., Zhang, H., Zhang, C., Qiu, Y., Wang, S.: Enhanced electrochemical properties of hierarchically sheath-core aligned carbon nanofibers coated carbon fiber yarn electrode-based supercapacitor via polyaniline nanowire array modification. J. Power Sources 399, 406-413 (2018)

23. Liu, B.-T., Syu, J.-R., Wang, D.-H.: Conductive polyurethane composites containing polyaniline-coated nano-silica. J. Colloid Interface Sci. 393, 138-142 (2013) 
24. Olad, A., Nosrati, R.: Preparation and corrosion resistance of nanostructured $\mathrm{PVC} / \mathrm{ZnO}$-polyaniline hybrid coating. Prog. Org. Coat. 76, 113-118 (2013)

25. Miao, Y., Xu, X., Liu, K., Wang, N.: Preparation of novel Cu/ $\mathrm{TiO}_{2}$ mischcrystal composites and antibacterial activities for Escherichia coli under visible light. Ceram. Int. 43, 9658-9663 (2017)

26. Geilich, B.M., van de Ven, A.L., Singleton, G.L., Sepúlveda, L.J., Sridhar, S., Webster, T.J.: Silver nanoparticle-embedded polymersome nanocarriers for the treatment of antibiotic-resistant infections. Nanoscale 7, 3511-3519 (2015)

27. Zhang, M., Zhang, C., Du, Z., Li, H., Zou, W.: Preparation of antistatic polystyrene superfine powder with polystyrene modified carbon nanotubes as antistatic agent. Compos. Sci. Technol. 138, 1-7 (2017)

28. Wang, Q., Wang, Y., Meng, Q., Wang, T., Guo, W., Wu, G., You, L.: Preparation of high antistatic HDPE/polyaniline encapsulated graphene nanoplatelet composites by solution blending. RSC Adv. 7, 2796-2803 (2017)

29. Hosseini, M.G., Sefidi, P.Y.: Electrochemical impedance spectroscopy evaluation on the protective properties of epoxy/DBSA doped polyaniline- $\mathrm{TiO}_{2}$ nanocomposite coated mild steel under cathodic polarization. Surf. Coat. Technol. 331, 66-76 (2017)

30. Rana, S.B., Bhardwaj, V.K., Singh, S., Singh, A., Kaur, N.: Influence of surface modification by 2-aminothiophenol on optoelectronics properties of $\mathrm{ZnO}$ nanoparticles. J. Exp. Nanosci. 9, 877-891 (2014)

31. Zhang, X., Wu, J., Meng, G., Guo, X., Liu, C., Liu, Z.: One-step synthesis of novel PANI- $\mathrm{Fe}_{3} \mathrm{O}_{4} @ \mathrm{ZnO}$ core-shell microspheres: an efficient photocatalyst under visible light irradiation. Appl. Surf. Sci. 366, 486-493 (2016)

32. Sharmin, E., Rahman, Ou, Zafar, F., Akram, D., Alam, M., Ahmad, S.: Linseed oil polyol/ZnO bionanocomposite towards mechanically robust, thermally stable, hydrophobic coatings: a novel synergistic approach utilising a sustainable resource. RSC Adv. 5, 47928-47944 (2015)

Publisher's Note Springer Nature remains neutral with regard to jurisdictional claims in published maps and institutional affiliations. 